\title{
SUPERIOR SULCUS LUNG TUMORS: IMPACT OF LOCAL CONTROL ON SURVIVAL
}

Michael P. Hagan, MD, PhDa

Noah C. Choi, MD

Douglas J. Mathisen, $\mathrm{MD}^{\mathrm{b}}$

John C. Wain, MD

Cameron D. Wright, $\mathrm{MD}^{\mathrm{b}}$

Hermes C. Grillo, MD $^{\mathrm{b}}$
Objectives: Our goal was to assess patient survival and response to treatment for superior sulcus tumors treated with combined radiation therapy and surgery when possible, or with radiation alone when surgery was not possible. Methods: Seventy-three patients were treated for primary non-small cell carcinoma of the superior pulmonary sulcus. Thirty-four patients received combined resection and irradiation. Thirty-nine patients who had extensive primary disease, distant metastases, or who were medically unfit for surgery were treated with radiation alone. Thirty-one patients $(91 \%)$ assigned to the resection/irradiation group completed treatment. Combined therapy patients routinely received $40 \mathrm{~Gy}$ before the operation, with additional postoperative irradiation based on the surgical findings. Results: Overall survival at 5 years was $19 \%$ and disease-specific survival was $20 \%$ for all patients. Overall survival and disease-specific survival at 5 years for the resection/irradiation group were $33 \%$ and $38 \%$, respectively. Significant indicators of poor prognosis included unresected primary disease, low performance score, T4 stage, or positive node status. Eighty-two percent of the patients who received irradiation alone were treated with palliative intent. Freedom from local-regional progression, achieved initially in $66 \%$ of these patients, was associated with a median survival of 8 months. Median survival for 7 patients considered for definitive irradiation was 25 months. During the first 18 months, distant failures occurred in approximately $35 \%$ of patients in each treatment group. Conclusions: Selection of medically fit patients with resectable disease for combined surgery and aggressive radiation therapy resulted in a high likelihood of local control. Overall survival for the resection/irradiation group was significantly poorer for patients with T4 stage, nodal disease, or Horner's syndrome. Distant metastases eventually developed in $\mathbf{5 6 \%}$ of patients undergoing resection. Median survival in the resection/irradiation group was significantly prolonged for those patients who could tolerate high-dose radiation treatment. (J Thorac Cardiovasc Surg 1999;117:1086-94)
$\mathrm{B}$ ronchogenic carcinomas arising from the superior pulmonary sulcus present with a distinctive constellation of symptoms first described in 1838 by Hare. ${ }^{1}$ In 1924 , and with an update in 1932, Pancoast ${ }^{2,3}$ identified

\footnotetext{
From the Departments of Radiation Oncology a and Thoracic Surgery, ${ }^{\mathrm{b}}$ Massachusetts General Hospital, Boston, Mass.

Received for publication March 12, 1998; revisions requested May 22, 1998; revisions received Jan 18, 1999; accepted for publication Feb 12, 1999.

Address for reprints: Michael P. Hagan, MD, Department of Radiation Oncology, Medical College of Virginia, PO Box 980058, 401 College St, Richmond, VA 23298.

Copyright (C) 1999 by Mosby, Inc.

$0022-5223 / 99 \$ 8.00+0 \quad \mathbf{1 2 / 1 / 9 7 9 1 8}$
}

these tumors as a distinct clinical entity. Today, however, the optimum therapy for carcinomas of the superior sulcus remains controversial.

The major impediment to the resolution of issues regarding treatment is the low incidence of these tumors. Owing to this, series involving tumors of the superior pulmonary sulcus are generally from single institutions, involve small numbers of patients, and are reported retrospectively. ${ }^{4-13}$ Thus the specific roles for radiation therapy and chemotherapy and the allegation of a unique pattern of metastasis remain uncertain. Recently reported series, however, suggest that the pattern of failure of these tumors is similar to that of bronchogenic carcinomas in general. ${ }^{5-13}$ As a result, superi- 


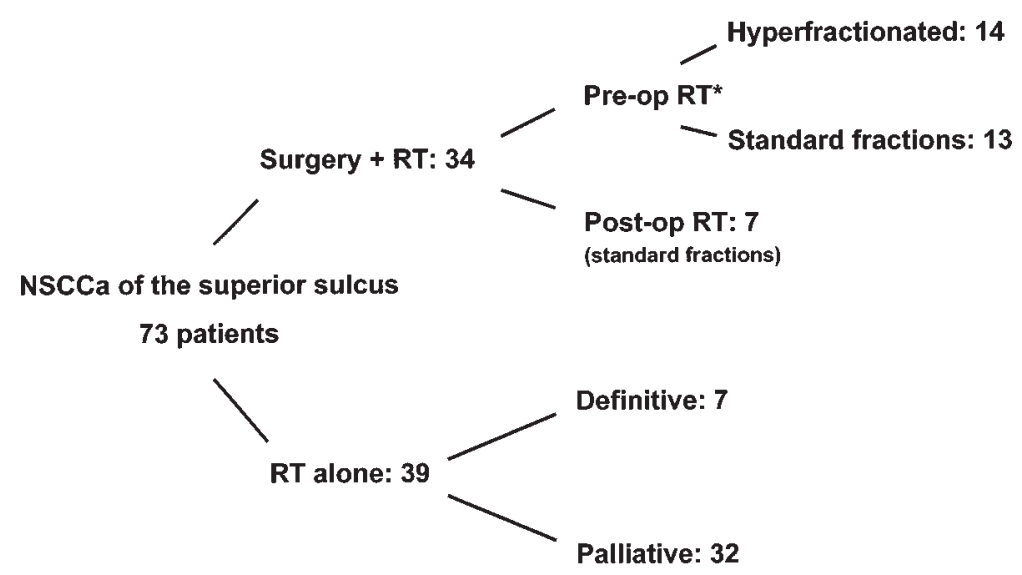

Fig 1. Patient grouping according to the assigned treatment. RT, Radiation therapy; NSCCa, non-small cell carcinoma. *Eleven patients also received postoperative radiation therapy.

or sulcus tumors are currently included with other stage IIIA/B non-small cell tumors for the intergroup study of neoadjuvant, adjuvant, or definitive chemotherapy and irradiation.

The present study, also retrospective from a single institution, includes not only patients treated for cure, but also those who received palliation. By including the entire institutional experience, the current study provides additional information about the natural history and pattern of failure of superior sulcus tumors.

During the period encompassed by this review, patients received surgical evaluation resulting in a recommendation for either combined surgery and irradiation or irradiation alone. Combined treatment was routinely recommended for patients with T3 primary tumors, negative results of mediastinoscopy, and no evidence of distant disease. Patients with T4 tumors or N2 nodal status (with a few exceptions) received radiation therapy alone. Although the population of patients includes both those with resected and those with unresected tumors, the study does not attempt to compare treatments. Instead, we present the results of a consistent set of treatment policies aimed at an aggressive attempt to secure local control in selected patients.

\section{Patients and methods}

Records reviewed for this retrospective study included those of all patients seen at Massachusetts General Hospital from January 1975 to January 1992 who had a diagnosis of lung cancer involving an upper lobe. From this cohort, the following patients were selected for inclusion: those coded as having non-small cell superior sulcus tumors, Pancoast tumors, or chest wall involvement and patients whose signs and symptoms included shoulder pain, upper extremity weakness, or Horner's syndrome. Patients with painful apical tumors were excluded when the tumor was completely contained within the visceral pleura, the painful site was limited to the anterior chest wall, or signs and symptoms of Pancoast's syndrome were absent. These criteria identified 73 patients.

Treatment selection. The assigned treatments are shown schematically in Fig 1 . Those patients without evidence of regional lymph node involvement, direct mediastinal invasion, extensive involvement of a vertebral body, or invasion into a neural foramina were treated for cure with combined resection and irradiation (the S+RT group). Most of these patients received preoperative irradiation followed by resection. Patients who did not meet these criteria received radiation treatment alone (the RT group), usually with palliative intent. In the palliated group, 16 patients had regional lymph node involvement, 15 had distant metastases either from the onset or discovered within the first 30 days of treatment, and for 14 patients the primary disease was too extensive to allow control by definitive irradiation. In the latter instance, the primary tumor was multilobar, involved a large region of the chest wall, or was larger than $10 \mathrm{~cm}$. In all, 34 patients were selected for combined surgery plus irradiation, whereas 39 received radiation therapy alone.

Of the 34 patients in the S+RT group, 27 received preoperative irradiation with 11 receiving additional postoperative radiation therapy. Seven patients treated before 1982 received only postoperative irradiation. Three patients scheduled for resection plus irradiation did not complete their treatment. All 3 completed preoperative irradiation, but afterward 2 had distant disease develop and 1 died of pneumonia. An additional patient died of pneumonia within 30 days of completing postoperative irradiation. This process, beginning as a pneumonitis restricted to the radiation portal, represents the sole radiation complication. The surgical techniques have been detailed elsewhere. ${ }^{9}$ Although we currently use an anterior approach when feasible, for the present series all tumors were resected en bloc via the posterior approach. 
Table I. Tumor characteristics

\begin{tabular}{|c|c|c|c|c|}
\hline \multirow[b]{2}{*}{ Characteristic } & \multicolumn{2}{|c|}{$S+R T$} & \multicolumn{2}{|c|}{$R T$} \\
\hline & $\begin{array}{l}\text { No. of } \\
\text { patients }\end{array}$ & $\%$ & $\begin{array}{l}\text { No. of } \\
\text { patients }\end{array}$ & $\%$ \\
\hline Non-small cell cancer & 34 & & 39 & \\
\hline \multicolumn{5}{|l|}{ T stage } \\
\hline $\mathrm{T} 3$ & 28 & 82 & 24 & 62 \\
\hline $\mathrm{T} 4$ & 6 & 18 & 15 & 38 \\
\hline \multicolumn{5}{|l|}{$\mathrm{N}$ stage } \\
\hline NX & 0 & & 19 & 49 \\
\hline No & 28 & 82 & 2 & \\
\hline N1 & 2 & & 4 & 10 \\
\hline $\mathrm{N} 2$ & 3 & & 9 & 23 \\
\hline $\mathrm{N} 3$ & 1 & & 5 & 13 \\
\hline $\begin{array}{l}\text { Maximum lesion } \\
\text { diameter }(\sigma)\end{array}$ & $\begin{array}{l}5.2 \mathrm{~cm} \\
(1.4 \mathrm{~cm})\end{array}$ & & $\begin{array}{l}5.7 \mathrm{~cm} \\
(2.2 \mathrm{~cm})\end{array}$ & \\
\hline \multicolumn{5}{|c|}{ Histology } \\
\hline \multicolumn{5}{|c|}{ Non-small cell carcinoma } \\
\hline Adenocarcinoma & 6 & 19 & 5 & 15 \\
\hline Large cell & 12 & 38 & 14 & 42 \\
\hline Squamous cell & 14 & 44 & 14 & 42 \\
\hline Unspecified & 2 & & 6 & \\
\hline
\end{tabular}

$S+R T$, Surgery plus radiation therapy; $R T$, radiation therapy.

Pretreatment evaluation. The initial evaluation of each patient routinely included history and physical examination, complete blood count, liver and renal function studies, and chest radiography. Other diagnostic work-up, reported as a percentage of the 73 patients in the total population, was performed as follows: computed tomography (CT) of the thorax $(85 \%)$, radionuclide bone scan $(93 \%)$, anterior mediastinoscopy or Chamberlain procedure (all patients undergoing resection and $66 \%$ of the total group), bronchoscopy (66\%), and CT scan or radionuclide scan of the head (48\%).

Irradiation. Radiation therapy was administered initially through parallel-opposed, anteroposterior-posteroanterior ports using megavoltage equipment. Fifty-eight patients were treated with $10-\mathrm{MV}$ photons, 5 with 2-MV photons, 10 with cobalt 60 , and 1 patient was treated with a combination of photon and proton irradiation. The treatment port routinely included the tumor with a 2-cm margin, ipsilateral hilum, mid-upper mediastinum, and ipsilateral or bilateral supraclavicular regions. The spinal cord was limited to $45 \mathrm{~Gy}$. Fourteen patients were treated twice daily with fraction sizes ranging from 1.4 to $1.8 \mathrm{~Gy}$. All other patients were treated daily at 1.8 to 2 Gy per exposure. Both fields were treated at each session, except in the 5 patients treated with 2-MV photons, for whom one field was treated each day. Typically, 40 Gy was given before the operation (range 30-45 Gy) with an additional $20 \mathrm{~Gy}$ given after the operation when lymph nodes were pathologically involved or when surgical margins were positive (diseased) or considered "close" by the reviewing pathologist. Seven patients treated before 1985 received only postoperative irradiation (range 50-64 Gy). For patients treated with radiation therapy alone, the radiation dose was dependent on individual physician preference.
Table II. Patient characteristics

\begin{tabular}{|c|c|c|}
\hline Characteristic & $S+R T$ & $R T$ \\
\hline Patients (n) & 34 & 39 \\
\hline Median age (y) & 57 & 62 \\
\hline Average KPS $(\sigma)$ & $82(8.6)$ & $74(21.6)$ \\
\hline Weight loss $(>10 \%)$ & $7(21 \%)$ & $17(44 \%)$ \\
\hline Smoking history >20 packs/year & $19(56 \%)$ & $24(62 \%)$ \\
\hline \multicolumn{3}{|l|}{ Presentation } \\
\hline Horner's syndrome & $6(21 \%)$ & $15(35 \%)$ \\
\hline Shoulder pain* & $27(90 \%)$ & $37(97 \%)$ \\
\hline Arm weakness $\dagger$ & $8(24 \%)$ & $22(56 \%)$ \\
\hline
\end{tabular}

Tumor characteristics. Tumor histologic type and staging are shown in Table I. Eighty-two percent of the patients treated with surgery plus irradiation had stage T3 disease, and only $18 \%$ had stage N1-N3 disease. For the patients who received irradiation alone, however, only $62 \%$ had stage T3 disease, whereas $46 \%$ had N1-N3 disease. The N0 findings for the patients in the RT group were based on mediastinoscopy. Patients without clinical or radiographic evidence of adenopathy were considered to have NX disease. The distributions of specific histologic types were similar for the RT and S+RT groups. Although the average size of the primary tumor treated by irradiation alone was greater, these determinations were radiologic for the patients treated with radiation alone and via radiologic information or pathologic review, usually after preoperative radiation therapy, for the resected lesions. For the S+RT group the largest diameter recorded is reported.

Data analysis. Response to treatment was analyzed for local control, distant metastasis, and survival. Outcome was assessed on the basis of the patient's originally assigned treatment. Local control was scored as freedom from clinical or radiographic evidence of local or regional progression. Survival values, determined by the life table method, ${ }^{14}$ involved the period from the time of diagnosis until initial failure or death. For disease-specific survival, 4 patients with no evidence of active cancer were censored because of death from unrelated causes. Three patients were from the combined S+RT group and 1 from the RT group. Follow-up was complete at 5 years or death, except for 2 patients who were lost to follow-up after 49 and 51 months, respectively. The Cox proportional hazard model was used to test the interaction of prognostic factors and treatment parameters. Proportional differences were assessed for significance by the $\chi^{2}$ test. The Welch modified Student $t$ test was used to evaluate differences in sample mean values.

\section{Results}

From 1975 to 1992,73 patients were referred to Massachusetts General Hospital for treatment of non-small cell carcinomas originating in the superior 
pulmonary sulcus. Forty-seven patients had stage IIIA disease and 26 had stage IIIB disease. Twenty-four patients $(33 \%)$ had pathologic or CT evidence of lymphadenopathy. Thirty-three percent reported a greater than $10 \%$ weight loss, and the average Karnofsky performance score was $76 .{ }^{15}$

Comparison of patient characteristics for S+RT versus RT groups. Thirty-four patients were treated with a combination of irradiation and resection. Criteria for their selection are listed in the Patients and methods section. Patients who did not meet these criteria or who had evidence of distant metastasis, regional lymph node involvement, mediastinal disease, extensive vertebral body involvement, or other unresectable disease received irradiation alone. Characteristics of the patients in each treatment group are shown in Table II. Patients in both groups were of similar average age and were equally likely to have had a painful brachial plexopathy. Patients meeting the criteria for resection, however, more frequently had stage IIIA disease, had a significantly higher Karnofsky status $(P=.0004)$, were less likely to have reported weight loss $(P=.005)$, and infrequently had Horner's syndrome or motor deficits involving the brachial plexus.

Survival for the combined group. Overall survival for the entire population is shown in Fig 2. There was no significant difference between overall survival and disease-specific survival for this population. The 5-year figures for overall and disease-specific survival were $19 \%$ and $20 \%$, respectively. The results of univariate analysis for overall survival are listed in Table III. Overall survival was greater for patients with Karnofsky performance status of 70 or greater $(P=$ $.01)$, patients with stage T3 disease $(P=.02)$, and nodenegative patients $(P=.00002)$. Disease-specific survival was significantly greater for the same parameters: Karnofsky status of 70 or greater $(P=.03)$, stage T3 disease $(P=.01)$, and no adenopathy $(P=.00002)$. Patients with greater than a $10 \%$ weight loss also showed a trend toward lower overall survival.

Survival and local control for patients undergoing resection. Overall survival and disease-specific survivals for all 34 patients selected for resection are shown in Fig 3. Overall survival for these patients was $42 \%$ at 2 years and $33 \%$ after 5 years. The corresponding disease-specific survival values were $49 \%$ and $38 \%$, respectively. Local control for this group, shown in Fig 4, was $80 \%$ after 5 years. Isolated local recurrences as the first site of recurrence were noted in only 3 patients. Univariate analysis, shown in Tables III and IV, for the patients undergoing resection demonstrated that overall survival but not local-regional control was significantly better for node-negative patients $(P=.05$
Table III. Univariate analysis: Overall survival

\begin{tabular}{|c|c|c|}
\hline \multirow[b]{2}{*}{ Parameter } & \multicolumn{2}{|c|}{$\mathrm{P}$ value (HR and $C I)^{*}$} \\
\hline & All patients & $S+R T$ group \\
\hline \multicolumn{3}{|l|}{ KPS } \\
\hline$<70$ & .01 & .95 \\
\hline$\geq 70$ & $(.708, .54-.93)$ & \\
\hline Ten percent weight loss & .16 & .86 \\
\hline Plexopathy & .97 & .24 \\
\hline Horner's syndrome & .29 & $.03(1.87,1.0-3.49)$ \\
\hline \multicolumn{3}{|l|}{ T stage } \\
\hline T3 vs T4 & $.02(1.37,1.05-1.78)$ & .51 \\
\hline \multicolumn{3}{|l|}{ Nodal status } \\
\hline \multicolumn{3}{|l|}{ All patients } \\
\hline N0 NX & .00002 & \\
\hline $\mathrm{N}+$ & $(3.26,1.85-5.73)$ & \\
\hline \multicolumn{3}{|l|}{ S+RT patients $\dagger$} \\
\hline NO & & .05 \\
\hline $\mathrm{N}+$ & & $(1.63,1.0-2.63)$ \\
\hline \multicolumn{3}{|l|}{ Fractionation } \\
\hline $\begin{array}{l}\text { Standard vs } \\
\text { hyperfractionated }\end{array}$ & ND & .18 \\
\hline \multicolumn{3}{|l|}{ Tumor size } \\
\hline $\begin{array}{l}\leq 5 \mathrm{~cm} \\
>5 \mathrm{~cm}\end{array}$ & .24 & .48 \\
\hline \multicolumn{3}{|l|}{ Margin status } \\
\hline $\begin{array}{l}\text { Positive } \\
\text { Negative }\end{array}$ & ND & .26 \\
\hline
\end{tabular}

$S+R T$, Surgery plus radiation therapy; KPS, Karnofsky performance score; $N O$, node-negative patients; $N+$, node-positive patients; $N X$, nodal status uncertain; $N D$, not done.

* $P$ values are the result of Cox proportional hazard analysis; the hazard ratio (HR) and confidence intervals (CI) are shown when the $P$ value is $\leq .05$. †For patients not undergoing resection, positive nodal status was determined by CT or mediastinoscopy. Patients with no radiographic evidence of node positivity were considered to be NX.

and $P=.55$, respectively). The absence of Horner's syndrome was also associated with significantly greater overall survival $(P=.03)$. Patients with negative (disease-free) surgical margins and T3 status had fewer local-regional failures.

Multivariate analysis. The results of multivariate analysis are shown in Table V. Multivariate analysis of prognostic factors for overall survival identified lymphadenopathy as the only significant factor $(P=.0055)$. For local-regional control, tumor size $(P=.031)$, $\mathrm{T}$ stage $(P=.017)$, and lymphadenopathy $(P=.042)$ were all significant predictors. When analysis was restricted to the S+RT group, no prognostic or treatment-related factors were significant.

Impact of positive microscopic margins. Within the S+RT group, 6 patients were considered to have stage $\mathrm{T} 4$ disease because of vertebral body involvement (4 patients), great vessel involvement (1 patient), or mediastinal extension (1 patient). Of these patients, 5 had microscopic evidence of positive margins. Two 


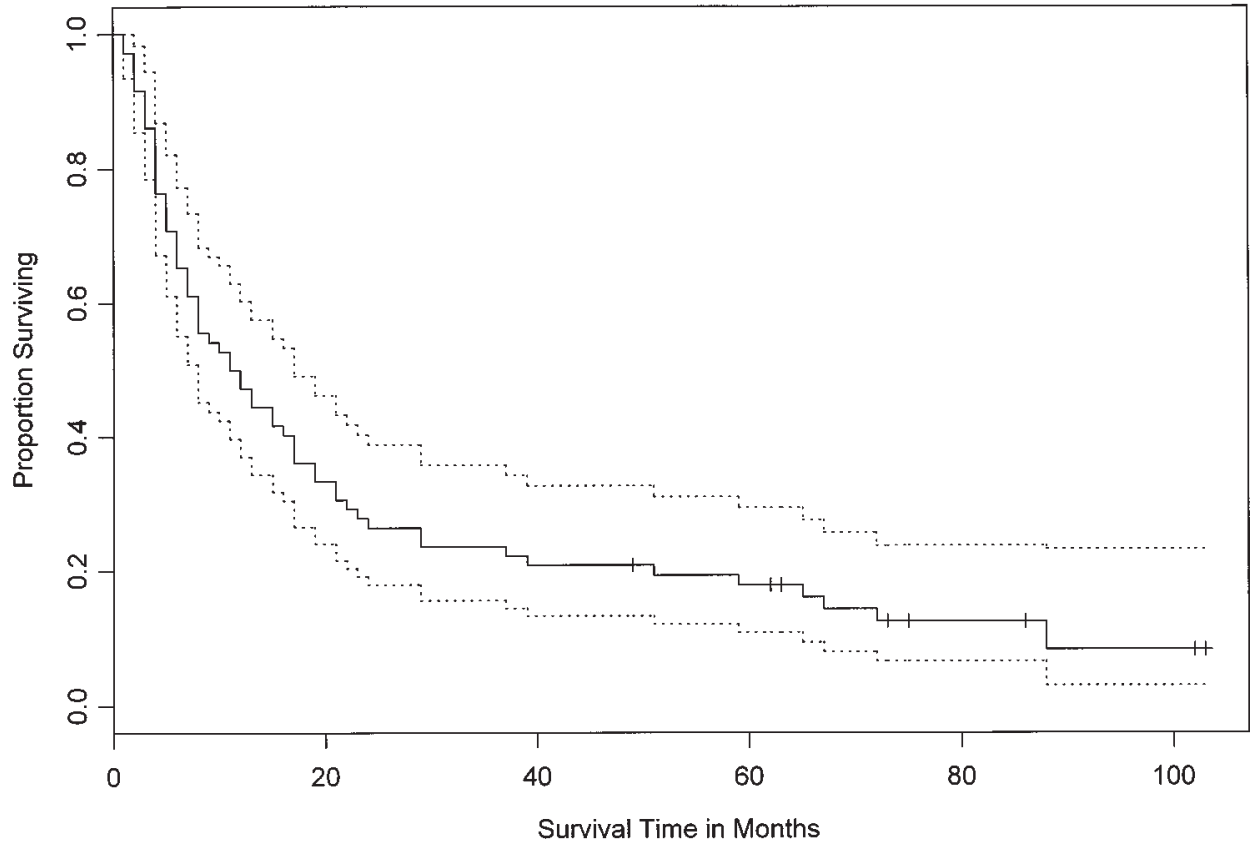

Fig 2. Kaplan-Meier actuarial survival curves for the entire patient group. Confidence intervals (95\%) are shown as broken lines.

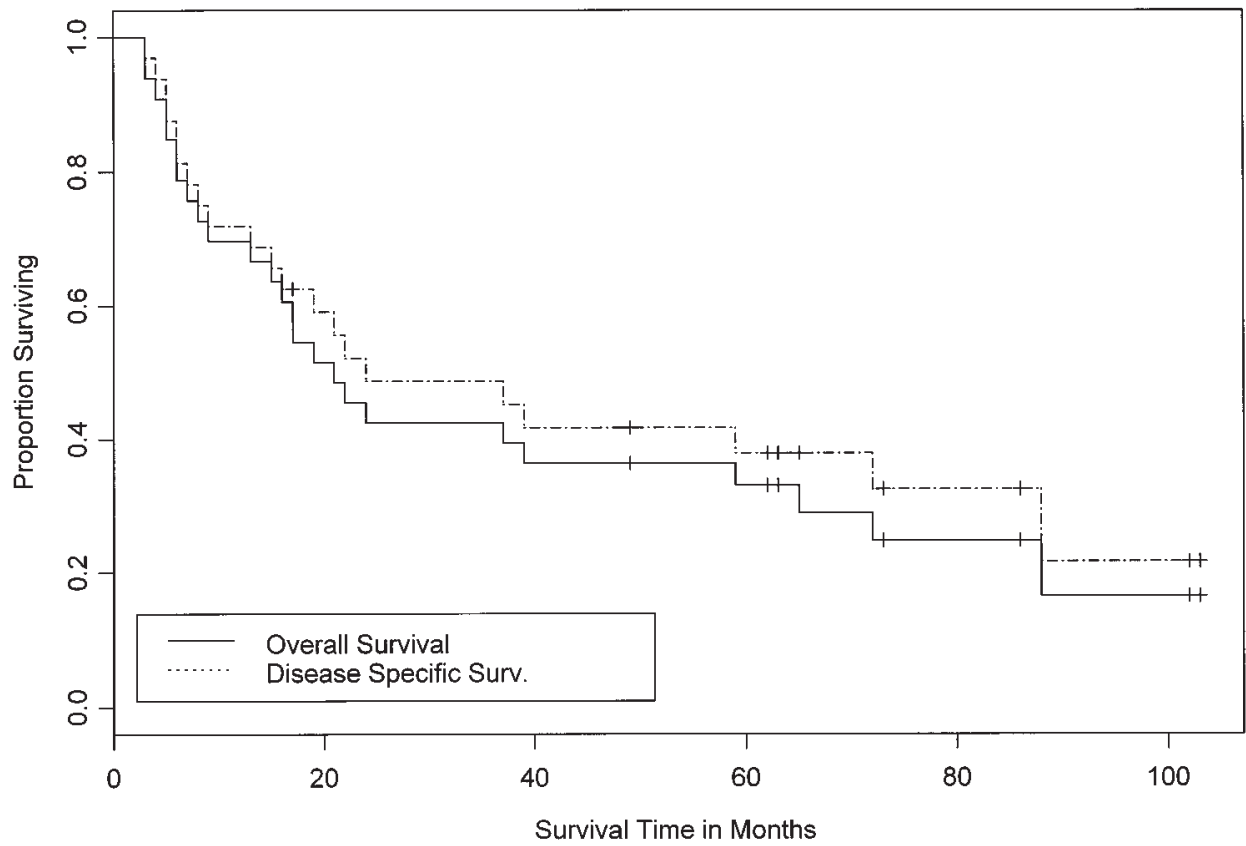

Fig 3. Kaplan-Meier actuarial overall and disease-specific survival curves for the patients undergoing combined surgery/radiation therapy. Confidence intervals were omitted to avoid confusion.

additional patients, with stage T3 disease, also had microscopically positive margins. Ultimately, 2 of these 7 patients with positive margins had local recur- rence, 1 had distant disease, and the disease status of another was uncertain. A microscopically positive surgical margin did not significantly affect survival but, on 


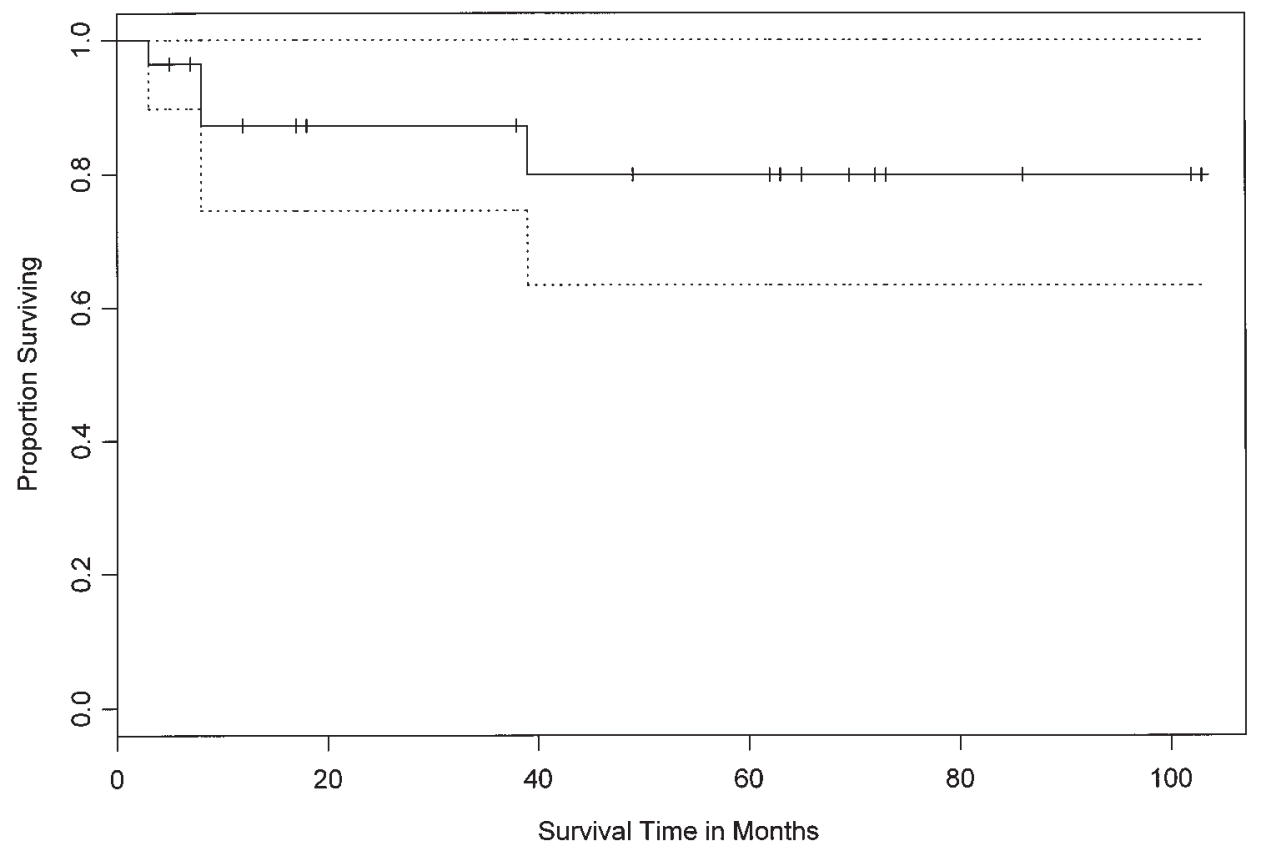

Fig 4. Kaplan-Meier curve for local control at the first site of failure (actuarial) for patients treated with surgery and irradiation.

univariate analysis, was associated with a greater likelihood of local-regional recurrence $(P=.02)$. In multivariate analysis of local-regional failures, however, margin status was not significant $(P=.34)$ when the sample was controlled for $\mathrm{T}$ stage.

Patients receiving irradiation alone (RT group). Thirty-nine patients were treated with radiation alone. For these patients overall survival after 5 years was $7 \%$.

Palliative response. Most patients who were not selected for resection (32/39 patients) received radiation therapy with the goal of providing durable palliation. Initial local control (scored as freedom from local progression) was achieved in $66 \%$ of these patients. The median duration of control was 15 months. Median survival for the palliated group, however, was only 34.8 weeks.

Definitive irradiation. Definitive irradiation was attempted in 7 patients in the RT group. These patients had no evidence of distant disease, had a primary tumor $6 \mathrm{~cm}$ or smaller, and had no sites of bulky adenopathy identified radiologically. For 1 patient with T4 N2 disease, spinal cord proximity limited the radiation dose to 54 Gy. Local control was not achieved. One patient (stage T3 N0 disease) for whom proximity of the spinal cord was not an issue received $73 \mathrm{~Gy}$. This patient survived for 67 months, having local-regional treatment failure after 53 months. For the remaining 5 patients the spinal cord dose was partially limiting. The average tumor dose was $65 \mathrm{~Gy}$. Median survival for this group was 25.2 months (range 12-51 months). Local failure eventually developed in 5 of 6 patients in this group for whom local control information was available.

Distant metastasis. The primary mode of treatment failure for both treatment groups was through distant disease. Actuarially, $47 \%$ of patients receiving combined surgery and irradiation had distant metastases within the first 5 years. The initial site of distant disease for 5 patients was the brain. Failure first occurred in the contralateral lung, adrenals, and skin for 1 patient each and was unrecorded in 2 patients. The median time to the appearance of distant metastasis in the S+RT patient group was 17 months. In the RT group, however, the median time to appearance of distant disease was less than 3 months. For each treatment group, distant failure was seen in approximately $35 \%$ of patients in the first 18 months. The S+RT group, by virtue of its greater proportion of patients with local control and hence patients at risk for distant failure, provided evidence for late distant failures. The last was recorded 71 months after the original diagnosis.

Lymphadenopathy and distant disease. For patients in the S+RT group, lymph node disease was associated with a greater risk of distant failure, but not local-regional failure. Overall, distant metastases eventually developed in $60 \%$ of patients with positive lymph nodes, whereas only $30 \%$ of node-negative 
Table IV. Univariate analysis: Local-regional control* $^{*}$

\begin{tabular}{|c|c|c|}
\hline \multirow[b]{2}{*}{ Parameter } & \multicolumn{2}{|c|}{$\mathrm{P}$ value (HR and CI) } \\
\hline & All patients & $S+R T$ group \\
\hline \multicolumn{3}{|l|}{ KPS } \\
\hline$<70$ & .0008 & .62 \\
\hline$\geq 70$ & $(.505, .337-.759)$ & \\
\hline Ten percent weight loss & $.03(.636, .421-.96)$ & .80 \\
\hline Plexopathy & .81 & .59 \\
\hline Horner's syndrome & .95 & .53 \\
\hline \multicolumn{3}{|l|}{ T stage } \\
\hline $\mathrm{T} 3$ & .005 & .02 \\
\hline $\mathrm{T} 4$ & $(1.73,1.2-2.5)$ & $(3.41,1.1-10.6)$ \\
\hline \multicolumn{3}{|l|}{ Nodal status } \\
\hline \multicolumn{3}{|l|}{ All patients } \\
\hline NO NX & $1.2 \times 10^{-6}$ & \\
\hline $\mathrm{N}+$ & $(9.23,3.1-27.5)$ & \\
\hline \multicolumn{3}{|l|}{ S+RT patients } \\
\hline NO & & .55 \\
\hline \multicolumn{3}{|l|}{$\mathrm{N}+$} \\
\hline \multicolumn{3}{|l|}{ Fractionation } \\
\hline $\begin{array}{l}\text { Standard vs } \\
\text { hyperfractionation }\end{array}$ & $.02(.503, .244-1.03)$ & .70 \\
\hline \multicolumn{3}{|l|}{ Tumor size $(\mathrm{cm})$} \\
\hline$\leq 5 \mathrm{~cm}$ & .01 & .19 \\
\hline$>5 \mathrm{~cm}$ & $(1.84,1.129-3.00)$ & \\
\hline \multicolumn{3}{|l|}{ Margin status } \\
\hline Positive & ND & .02 \\
\hline Negative & & $(3.41,1.1-10.6)$ \\
\hline
\end{tabular}

$\overline{H R}$, Hazard ratio; $C I$, confidence intervals; $S+R T$, Surgery plus radiation therapy; $R T$, radiation therapy; KPS, Karnofsky performance score.

*Scored as freedom from local progression.

patients were similarly affected. Twenty-seven patients in the S+RT group, for whom pathologic evaluation of lymph node status was uniformly obtained, could be evaluated for distant disease. Distant disease occurred in $22 \%$ of those who were node negative and in all 4 patients who were lymph node positive. Regardless of the treatment group, no patient with lymphadenopathy survived longer than 22 months.

\section{Discussion}

This series includes all patients with a primary non-small cell carcinoma of the superior pulmonary sulcus treated at the Massachusetts General Hospital from 1975 to 1992. Every effort was made to exclude patients with apical tumors or patients whose tumor secondarily invaded the superior sulcus. All tumors were staged either $\mathrm{T} 3$ or $\mathrm{T} 4$, with the chest wall representing the most common site of extension. The nodal incidence, which for superior sulcus tumors varies considerably from series to series, ${ }^{10-13}$ was $18 \%$ for patients undergoing resection and $33 \%$ overall. In 15
Table V. Multivariate analysis: All patients

\begin{tabular}{|c|c|c|}
\hline \multirow[b]{2}{*}{ Parameter } & \multicolumn{2}{|c|}{$\mathrm{P}$ value (HR and $C I)^{*}$} \\
\hline & Overall survival & Local control \\
\hline \multicolumn{3}{|l|}{ KPS } \\
\hline$<70$ & .07 & \\
\hline$\geq 70$ & $(.775, .59-1.02)$ & \\
\hline \multicolumn{3}{|c|}{ Tumor size $(\mathrm{cm})$} \\
\hline$\leq 5 \mathrm{~cm}$ & & .031 \\
\hline$>5 \mathrm{~cm}$ & & $(1.985,1.064-3.70)$ \\
\hline \multicolumn{3}{|l|}{ T stage } \\
\hline $\mathrm{T} 3$ & & .017 \\
\hline $\mathrm{T} 4$ & & $(1.688,1.10-2.59)$ \\
\hline \multicolumn{3}{|c|}{ Nodal status } \\
\hline N0 NX & .0055 & .042 \\
\hline $\mathrm{N}+$ & $(2.48,1.31-4.71)$ & $(6.868,1.833-25.73)$ \\
\hline
\end{tabular}

patients (20\%) distant metastases were either present on admission or developed within 30 days of diagnosis.

Patients were offered combined surgery and irradiation if they had resectable primary disease, had no contraindication for irradiation, had no evidence of distant disease, and had mediastinoscopic results negative for involvement. This selection resulted in 3 distinct patient populations illustrated in Fig 1.

This degree of selection is typical of those series that include an institution's entire experience. In the 6 other series that report results of both palliative and curative treatments, the rate of resection varied from $29 \%$ to $58 \% .^{7,12,13,16,17}$ Overall 5-year survival for the patients undergoing resection from these series averaged $31 \%$. Survival for the largely palliatively treated patients not undergoing resection was 5\% from the same series. These results are similar to the values reported here (5year overall survival of $33 \%$ with a resection rate of $42 \%$, and a $7 \%$-year survival for the patients not having resection). Interestingly, none of these results for patients undergoing resection differs significantly from the results of the seminal series reported by Paulson ${ }^{5}$ and Maggi and colleagues ${ }^{18}$ (35\% 5-year survival and a $64 \%$ rate of resection).

The obvious aim of combined treatment is to improve survival by securing local-regional control of disease. When extension to adjacent structures impedes surgical resection of the tumor, preoperative irradiation has proven useful. Generally, irradiation in the preoperative setting reduces morbidity by requiring lower radiation doses and smaller treatment volumes. Preoperative irradiation also reduces the likelihood of 
spilling viable tumor cells and may improve the resectability. In addition to superior sulcus tumors, the resection of locally advanced carcinomas of the breast, ${ }^{19}$ rectum, ${ }^{20}$ and esophagus ${ }^{21}$ and of sarcomas ${ }^{22}$ has been assisted through this maneuver.

Altered fractionation schedules for the preoperative irradiation, specifically, hyperfractionation and accelerated hyperfractionation, are frequently associated with improved local control. ${ }^{23-25}$ For this series, the irradiation component evolved from daily exposures (delivering 30 Gy before the operation) to an aggressive program consisting of accelerated hyperfractionation delivering $40 \mathrm{~Gy}$.

Before the routine use of $\mathrm{CT}$, few reports attempted to quantify local control of tumors involving the superior sulcus. In recent reports, however, local control has been remarkably similar for series reporting results of combined irradiation and resection. Komaki and associates ${ }^{11}$ reported $86 \%$ local control for combined modality patients at the M. D. Anderson Hospital, and Maggi and colleagues $^{18}$ reported a similar figure, $85 \%$, from the Turin series. Remmen and coworkers ${ }^{26}$ have reported 2 local failures in 5 years in a small series (10 patients at risk) from Nijmegen and Groesbeek. In the present series, local control was achieved in $91 \%$ of patients undergoing resection, and for $80 \%$ of the patients, local control was maintained for more than 5 years. No local failures were documented for the 11 patients in the $\mathrm{S}+\mathrm{RT}$ group who received irradiation twice daily.

When the surgical margin was close or positive, postoperative irradiation was delivered. In previous reports, the use of postoperative irradiation to salvage partially resected superior sulcus tumors has been largely unsuccessful. Series from the University of California at Los Angeles $^{27}$ and from Turin ${ }^{18}$ reported no 5-year survivors after postoperative irradiation. At the Memorial Sloan-Kettering Cancer Center, although patients with partially resected tumors routinely received postoperative brachytherapy, their 5-year survival was less than $10 \% 28$ and not different from the survival of patients not undergoing resection. In the present series, however, 14 patients with close or positive margins received postoperative irradiation. Eleven had no local-regional failures and 7 patients were 5-year survivors.

Patients whose primary tumors were unresected received irradiation alone. Although the intent of this treatment was not always clearly stated, many patients received low-dose palliative treatment. However, a small group of these patients was potentially curable. Seven patients were medically fit, and their primary disease, which was relatively small $(<6 \mathrm{~cm})$, was not associated with distant disease or bulky adenopathy. In
6 of these patients, either the radiation dose or the field size was limited because of proximity to the spinal cord. Treatment failed locally in 5 of these 6 patients. The single patient who received adequately placed high-dose irradiation survived more than 5 years but had a late local failure. These results illustrate both the need for and the difficulty in delivering definitive irradiation to the superior sulcus.

It is clear from this series, and the several others described in this report, that through the use of aggressive local treatment long-term local-regional control can be achieved for a high percentage of patients who are candidates for resection. Unfortunately, distant metastases will eventually develop in approximately half of these patients. Thus, in the absence of earlier diagnosis, improved long-term survival will require better systemic therapy.

In the setting of carcinomas of the superior sulcus, chemotherapy data are scarce, preventing meaningful interpretation. For example, Martinez-Monge and coworkers $^{29}$ reported a 56\% 4-year survival for 18 patients treated with preoperative chemotherapy and radiation therapy, but Ginsberg and associates ${ }^{28}$ reported no long-term survivors from a group of 10 patients treated with neoadjuvant chemotherapy.

There is evidence, however, that chemotherapy increases survival in the setting of other IIIA/IIIB non-small cell lung cancers. Positive results have been reported from 2 trials of preoperative platinum-based chemotherapy and radiation therapy. ${ }^{30,31}$ These encouraging results have established the basis for a current intergroup trial studying induction chemotherapy and radiation therapy for carcinomas of the superior sulcus.

Our current approach for tumors of the superior sulcus incorporates 2 cycles of platinum-based chemotherapy in the neoadjuvant setting. This is followed by twice daily irradiation in a concomitant boost format. Three to 4 weeks later the tumor is resected en bloc either via the posterior approach or, when appropriate, through an anterior approach.

In summary, resection and adjuvant irradiation produced excellent local control of superior sulcus tumors. This degree of regional disease control was associated with a 5-year overall survival of $33 \%$. Although few patients had positive surgical margins, adjuvant irradiation appears to have controlled the disease in most patients. Distant metastasis was the most frequent mode of first failure.

Both the high percentage of patients receiving only palliative care and the dismal prognosis for patients with positive lymph nodes of high $\mathrm{T}$ stage are consistent with the outcome for bronchogenic carcinomas 
from other sites. Thus the discordance of high survival associated with lesions of high T stage, for which superior sulcus tumors are known, appears to be more of an artifact of the staging system than evidence of an unusual natural history.

\section{REFERENCES}

1. Hare ES. Tumor involving certain nerves. Lond Med Gaz 1938; $1: 16$.

2. Pancoast HK. Importance of careful roentgen-ray investigations of apical chest tumors. JAMA 1924;83:1407-11.

3. Pancoast HK. Superior pulmonary sulcus tumor: tumor characterized by pain, Horner's syndrome, destruction of bone and atrophy of hand muscles. JAMA 1932;99:1391-6.

4. Van Houtte P, Rocmans P. Do superior sulcus tumors have a better prognosis than other lung cancer sites? [editorial]. Int J Radiat Oncol Biol Phys 1990;19:823.

5. Paulson DL. Carcinomas of the superior pulmonary sulcus. J Thorac Cardiovasc Surg 1975;70:1095-104.

6. Miller JI, Mansour KA, Hatcher CR Jr. Carcinoma of the superior pulmonary sulcus. Ann Thorac Surg 1979;28:44-7.

7. Attar S, Miller JE, Satterfield J, et al. Pancoast's tumor: Irradiation or surgery? Ann Thorac Surg 1979;28:578-86.

8. Van Houtte P, MacLennan I, Poulter C, Rubin P. External radiation in the management of superior sulcus tumor. Cancer 1984; 54:223-7.

9. Wright CD, Moncure AC, Shepard JA, Wilkins EW, Mathisen DJ, Grillo HC. Superior sulcus lung tumors: results of combined treatment (irradiation and radical resection). J Thorac Cardiovasc Surg 1987;94:69-74.

10. Shahian DM, Neptune WB, Ellis FH Jr. Pancoast tumors: improved survival with preoperative and postoperative radiotherapy. Ann Thorac Surg 1987;43:32-8.

11. Komaki R, Roh J, Cox JD, Lopes da Conceicao A. Superior sulcus tumors: results of irradiation of 36 patients. Cancer 1981;48: 1563-8.

12. Komaki R, Mountain CF, Holbert JM, et al. Superior sulcus tumors. Int J Radiat Oncol Biol Phys 1989;19:31-6.

13. Neal CR, Amdur RJ, Mendenhall WM, Knauf DG, Block AJ, Million RR. Pancoast tumor: radiation therapy alone versus preoperative radiation therapy and surgery. Int J Radiat Oncol Biol Phys 1991;21:651-60.

14. Kaplan EL, Meier P. Nonparametric estimation from incomplete observations. J Am Stat Assoc 1958;53:457-81.

15. Karnofsky DA, Burchenal JH. The clinical evaluation of chemotherapeutic agents in cancer. In: MacLeod CM, editor. Evaluation of chemotherapeutic agents. Symposium. Microbiology section. New York Academy of Medicine. New York: Columbia University Press; 1949. p. 191-205.
16. Stanford W, Barnes RP, Tucker AR. Influence of staging in superior sulcus (Pancoast) tumors of the lung. Ann Thorac Surg 1995; 29:406-9.

17. Schraube P, Latz D. Wertigkeit der Strahlentherapie bei der Behandlung des Pancoast-tumors der Lunge. Strahlenther Onkol 1993;169:265-9.

18. Maggi G, Casadio C, Pischedda F, et al. Combined radiosurgical treatment of Pancoast tumor. Ann Thorac Surg 1994;57:198202.

19. Rodger A, Montague E, Fletcher GH. Preoperative and postoperative irradiation as an adjunctive treatment with radical mastectomy in breast cancer. Cancer 1983;51:1388-92.

20. Tobin RL, Mohiuddin M, Marks G. Preoperative irradiation for cancer of the rectum with extrarectal fixation. Int J Radiat Oncol Biol Phys 1991;21:1127-32.

21. Leichman L, Steiger Z, Seydahl HG, et al. Preoperative chemotherapy and radiation therapy for patients with cancer of the esophagus: a potentially curative approach. J Clin Oncol 1984; 2:75-9.

22. Suit HD, Mankin HJ, Hood WC, et al. Radiation and surgery in the treatment of primary sarcoma of soft tissue: preoperative, intraoperative, and postoperative. Cancer 1985;55:2659-67.

23. Ang KK. Altered fractionation in the management of head and neck cancer. Int J of Radiat Biol 1998;73:395-9.

24. Fowler JF. Review: total doses in fractionated radiotherapyimplications of new radiobiological data. Int J Radiat Biol 1996; 46:103-29.

25. Coucke PA, Sartorelli B, Cuttat J, Jeanneret W, Gillet M, Miramanoff $\mathrm{R}$. The rationale to switch from postoperative hyperfractionated accelerated radiotherapy to preoperative hyperfractionated accelerated radiotherapy in rectal cancer. Int J Radiat Oncol Biol Phys 1995;32:181-8.

26. Remmen HJ, Lacquet LK, Van Son JA, Morshuis WJ, Cox AL. Surgical treatment of Pancoast tumor. J Cardiovasc Surg (Torino) 1993;34:157-61

27. Anderson TM, Moy PM, Holmes EC. Factors affecting survival in superior sulcus tumors. J Clin Oncol 1986;4:1598-603.

28. Ginsberg RJ, Martini M, Zaman M, et al. Influence of surgical resection and brachytherapy in the management of superior sulcus tumor. Ann Thorac Surg 1994;57:1440-5.

29. Martinez-Monge R, Herreros J, Aristu JJ, Aramendia JM, Azinovic I. Combined treatment in superior sulcus tumors. Am J Clin Oncol 1994;17:317-22.

30. Rusch VW, Albain KS, Crowley JJ, et al. Surgical resection of stage IIIa and IIIb non-small-cell lung cancer after concurrent induction chemoradiotherapy. J Thorac Cardiovasc Surg 1993; 105:97-106.

31. Yashar J, Weitberg AB, Glicksman AS, Posner MR, Feng W, Wanebo HJ. Preoperative chemotherapy and radiation therapy for stage IIIa carcinoma of the lung. Ann Thorac Surg 1992;53:445-8. 